\title{
CFD analysis of biodiesel combustion applied to industrial burners
}

\author{
Antonio Cantiani $^{1 *}$, Annarita Viggiano ${ }^{1}$, Emanuele Fanelli ${ }^{2}$, Giacinto Cornacchia ${ }^{2}$, Giacobbe Braccio $^{2}$, Vinicio Magi $^{1}$ \\ ${ }^{1}$ School of Engineering, University of Basilicata, Potenza 85100, Italy \\ ${ }^{2}$ ENEA - Italian National Agency for New Technologies, Energy and Sustainable Economic Development, Rotondella 75026, \\ Italy
}

Corresponding Author Email: cantiani.a@gmail.com

https://doi.org/10.18280/mmc_c.790301

Received: 7 April 2018

Accepted: 7 May 2018

\section{Keywords:}

biodiesel combustion, CFD, industrial burner, power generation

\begin{abstract}
The aim of this work is the analysis of the characteristics of biodiesel combustion in industrial burners in order to optimize the overall combustion process. A CFD model has been employed to simulate the fuel atomization process and the liquid spray evaporation that occur in a burner. A pressure swirl atomizer has been considered and a "flamelet" model has been implemented to simulate the fuel combustion. The validation of the numerical model has been carried out by a comparison with the experimental data provided by NIST (National Institute for Standards and Technology) for methanol injection and combustion in a cylindrical vessel with an injector axially located. The model has been employed to analyze the behavior of biodiesel fuel, inside the NIST burner, and to make a comparison with the injection and combustion of methanol. Biodiesel has been modelled as methyl-decanoate. A parametric study, by varying the injector included half-angle and the inlet air mass flow rate, has been carried out in order to identify an optimal configuration in terms of flame temperature and pollutant distributions as a result of the combustion process.
\end{abstract}

\section{INTRODUCTION}

The growing energy consumption leads the modern society to search for renewable energy. Specifically, the current policy adopted by the European Union is trying to find alternative and low environmental impact energy sources. Biofuels perfectly match these requirements. Indeed, the use of such fuels has doubled in the period 2010-2015 [1].

Biodiesel fuel essentially consists of Fatty Acid Methyl Esters (FAME) and is obtained starting from organic matter of vegetal or animal origin [2-3]. The thermodynamic properties of biodiesel fuel are similar to standard diesel fuel, which makes it suitable for industrial burners and internal combustion engines. Biodiesel, with respect to the standard diesel fuel, presents a good biodegradability, a low content of sulfur and low $\mathrm{CO}$ and soot emissions [4]. In addition, since it is produced from vegetable or animal matter, biodiesel can be easily produced in several different locations.

Biodiesel could be obtained from waste materials [5-7]. For instance, biodiesel is a secondary product of the syngas production process in ENEA (Italian national agency for new technologies, energy and sustainable economic development) laboratories [8]. Therefore, instead of storing and managing it as an industrial waste, biodiesel can be used as an additional energy source.

The aim of this work is to provide a CFD model that is able to predict the behavior of biodiesel combustion in industrial burners. The model is used to optimize the combustion process in terms of temperature distribution and pollutant emissions in the environment.

A standard procedure to improve the combustion characteristics of biodiesel fuel combines such a fuel with standard diesel and other fuels, such as $\mathrm{CH} 4$, methanol or ethanol, [9-10]. However, in [11] it has been shown that it is possible to optimize a swirl burner in order to achieve pure biodiesel combustion. References [9] and [12] provide a comparison on how biodiesel fuel leads to reduced pollutants and better flame stability with respect to diesel fuel in industrial burners.

This work is organized as follows: at first, the test case is described, then the numerical model is given, the results are discussed both for methanol and biodiesel combustion, and finally the conclusions are summarized.

\section{TEST CASE}

The NIST (National Institute of Standards and Technology) SCT (Spray Combustion Test-bed) benchmark [13-15] has been chosen as a comparison. NIST carried out several experimental investigations on methanol injection and combustion in a burner by using their facility. The model validation has been carried out by comparing NIST measurements with computational results, in terms of several parameters at different axial distances, such as velocity components of inlet air, injected droplets velocity and droplets diameter distribution.

The model validation has been performed by using methanol since the data provided by NIST regards the combustion of such a fuel. Since methanol and biodiesel have different physical/chemical properties, the numerical simulations performed by using biodiesel are preliminary, and the results can be used to provide useful recommendations on the design of a test-bench for biodiesel combustion in order to carry out experimental measurements. 


\subsection{Experimental setup}

The NIST SCT is made up by a cylindrical vessel with a diameter equal to $812.8 \mathrm{~mm}$ and height equal to $1244.6 \mathrm{~mm}$, as shown in Figure 1. The exhaust pipe is placed on the side wall of the cylinder. The fuel injector with a concentric air inlet are axially located at the bottom of the vessel. Both fuel injector and air inlet are placed at $200 \mathrm{~mm}$ from the bottom of the vessel. The air is injected with a swirl to get a tangential and a radial component of velocity. The swirl chamber vanes can be adjusted to achieve different swirl numbers at the combustion chamber inlet.

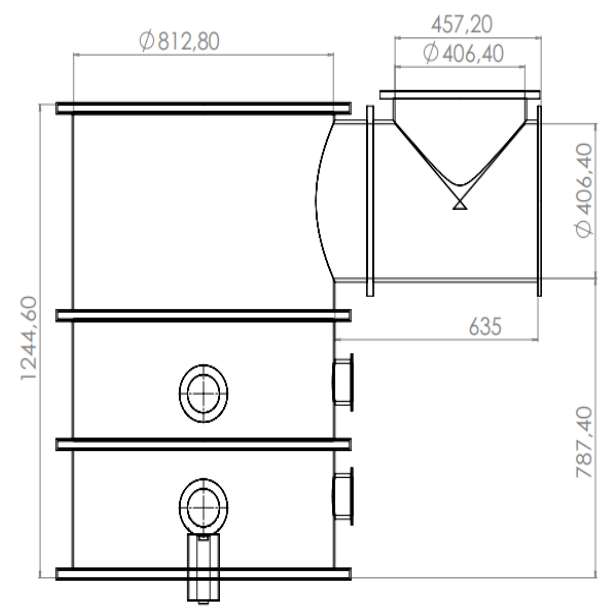

Figure 1. NIST SCT, technical drawing

Measurements have been carried out with a laser-doppler velocimeter by means of two optical ports placed at $9.5 \mathrm{~mm}$ and $17.6 \mathrm{~mm}$ from the injector. Gas velocity components and diameter and axial velocity of the injected liquid drops have been measured, with and without combustion.

The injector is a pressure swirl atomizer (or simplex atomizer). In this type of injector, the liquid fuel is initially accelerated by a nozzle, then it enters into a swirl chamber. Based on such a swirl, at the exit of the injector the liquid takes a hollow-cone form, which is typical of pressure swirl atomizers.

Table 1 summarizes the main specifics of the atomizer, the fuel injection and the air inlet.

\subsection{Experimental data}

Table 1. Benchmark setup

\begin{tabular}{cc}
\hline Atomizer & \\
\hline Type & $\begin{array}{c}\text { Delavan WDA14-1.0 Simplex } \\
\text { atomizer }\end{array}$ \\
\hline Material & Stainless steel \\
\hline Injection type & Hollow-cone $60^{\circ}$ \\
\hline Fuel & Methanol \\
\hline Type & $3 \mathrm{~kg} / \mathrm{h}$ \\
\hline Mass flow & $293 \mathrm{~K}$ \\
\hline Temperature & $689 \mathrm{kPa}$ \\
\hline Injection pressure & $56.7 \mathrm{~m}^{3} / \mathrm{h}$ \\
\hline Combustion air & $50^{\circ}$ \\
\hline Volumetric flow & \\
\hline $\begin{array}{c}\text { Swirl chamber blades } \\
\text { inclination }\end{array}$ &
\end{tabular}

The experimental data provided by NIST are:
(1) air inlet boundary conditions;

(2) axial, tangential and radial gas velocity components at $9.5 \mathrm{~mm}$ and $17.6 \mathrm{~mm}$ from the injector exit (both with and without combustion);

(3) Sauter mean diameter of the droplets measured from 5 $\mathrm{mm}$ to $65 \mathrm{~mm}$ from the injector at intervals of $5 \mathrm{~mm}$ (without combustion);

(4) injected droplets velocity profile from $5 \mathrm{~mm}$ to $65 \mathrm{~mm}$ from the injector at intervals of $5 \mathrm{~mm}$ (without combustion).

These data have been used to validate the CFD model.

\section{CFD MODEL}

In this section, the mathematical model is described and details about the computational domain and the mesh are also provided. All the simulations have been performed by using Ansys Fluent 18.2 Academic version. The computational domain has been obtained with Ansys Design Modeler, whereas the mesh with Ansys meshing software.

\subsection{Mathematical model}

The Reynolds Averaged Navier-Stokes equations have been solved by using the RNG k- $\varepsilon$ turbulence model based on the Renormalization Group theory. This model, compared to the standard $k-\varepsilon$ model, is more accurate for swirling flows, and is able to compute the effective viscosity for low Reynolds numbers [16]. These features make the RNG k- $\varepsilon$ turbulence model accurate for a wider variety of turbulent flows. The actual system of equations and more details about this model can be found in the Ansys Fluent Theory Guide [17].

The pressure swirl atomizer is simulated by using the LISA (Linearized Instability Sheet Atomization) model to describe the primary breakup. The LISA model contemplates a liquid sheet at the exit of the injector that surrounds an air core. The sheet thickness, $t$, depends on the mass flow rate, $\dot{m}$, the axial velocity component of the injected liquid at the injector exit, $u$, the injected liquid density, $\rho_{l}$, and the injector orifice diameter, $d_{i n j}$, according to the following equation:

$\dot{m}=\pi \rho_{l} u t\left(d_{i n j}-t\right)$

The velocity component $u$ is determined by the semiempirical relation (Eq. 2) proposed by Han et al. [18]:

$u=k_{v} \sqrt{\frac{2 \Delta p}{\rho_{l}}} \cos (\vartheta)$

where $\Delta p$ is the pressure drop inside/outside the injector, $\vartheta$ is the spray angle and $k_{v}$ is a velocity coefficient that depends on the injector geometry. An expression for such a coefficient is:

$k_{v}=\max \left(0.7, \frac{4 \dot{m}}{d_{0}^{2} \rho_{l} \cos \vartheta} \sqrt{\frac{\rho_{l}}{2 \Delta p}}\right)$

where $d_{0}$ is the most probable droplet size (see [18] for further details). Once the sheet is formed, the LISA model includes the effects on it of the surrounding gas. Specifically, it considers a two-dimensional sheet wrinkled by pressure waves, which determine fluctuations of velocity and pressure on both the liquid and the gas phase, resulting into the development of the Kelvin-Helmholtz instability. The propagation of this instability causes the primary breakup. 
The secondary breakup is accounted for by using the TAB (Taylor Analogy Breakup) model. This model is based on the analogy between a mass-spring dumped system and a deforming liquid drop. The differential equation governing the model descends from the differential equation for mass-spring dumped systems, as follows:

$C_{F} \frac{\rho_{g} u_{d}^{2}}{\rho_{l} r}-C_{k} \frac{\sigma}{\rho_{l} r^{3}} x-C_{d} \frac{\mu_{l}}{\rho_{l} r^{2}} \frac{d x}{d t}=\frac{d^{2} x}{d t^{2}}$

where the model constants $C_{F}=1 / 3, C_{k}=8$ and $C_{d}=5$ are experimentally derived [16], $x$ is the droplet distortion at any given time $t, \rho_{g}$ is the gas phase density, $u_{d}$ is the relative velocity of the droplet, $r$ is the undisturbed droplet radius, $\sigma$ is the droplet surface tension, and $\mu_{l}$ is the droplet viscosity. When $x>0.5 r$ the droplet brakes into two smaller droplets. More details about this model can be found in [17].

Besides, the stochastic collision model and the coalescence model have been enabled. Coalescence and collision of droplets are determined by a statistical approach [19]. Once the collision between two droplets occurs, the choice on whether they bounce or they form a bigger droplet (coalescence) depends on the Weber collision number $W e_{c}$, which depends on the droplet density $\rho_{l}$, the relative velocity between the two droplets $U_{\text {rel }}$, the droplet surface tension $\sigma$, and the mean diameter of the two droplets $\bar{D}$, according to the following equation:

$W e_{c}=\frac{\rho_{l} U_{r e l}^{2} \bar{D}}{\sigma}$

The drag law used is the dynamic drag, which adjusts the drag on the liquid droplets according to their shape. The drag coefficient is determined by:

$C_{d}=C_{d, s p h}(1+2.632 y)$

where $C_{d, s p h}$ is the drag coefficient of an ideal spherical droplet and $y$ is the droplet distortion parameter, defined as:

$y=\frac{x}{C_{b} r}$

where $C_{b}$ is an empirical constant.

As regards combustion, a non-premixed model is used. The equations [17] are written in terms of the mixture fraction, which represents the mass fraction of all the elements originating from the fuel. As regards kinetics, the "chemical equilibrium" assumption for methanol is employed, thus computing the chemical source term with a single global reaction.

On the other hand, a chemical kinetic reaction mechanism for biodiesel has been used to get more accurate results. Specifically, methyl decanoate is used as representative of biodiesel. Among the reaction mechanisms available in the literature, a skeletal reaction mechanism with 118 chemical species and 837 reactions [20] has been chosen.

\subsection{Computational domain}

Since the aim of this work is to determine the flame structure of biodiesel combustion, it is reasonable to assume that the flow field in the burner far away from the flame does not significantly affect the flame itself. For this reason, the simulation domain (red marked in Figure 2) has been restricted to a region near the flame, with a height of $600 \mathrm{~mm}$ from the injector.

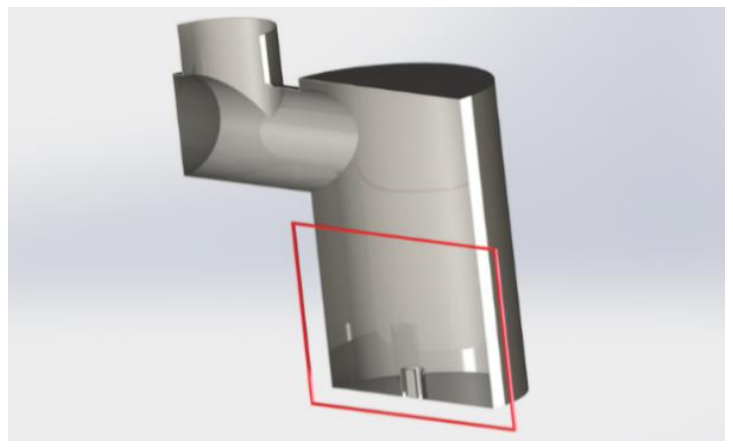

Figure 2. Cross section of the burner

Besides, based on the axial symmetry of the combustor, the analysis has been restricted to a sector of $30^{\circ}$, as shown in Figure 3, to reduce the computational cost.

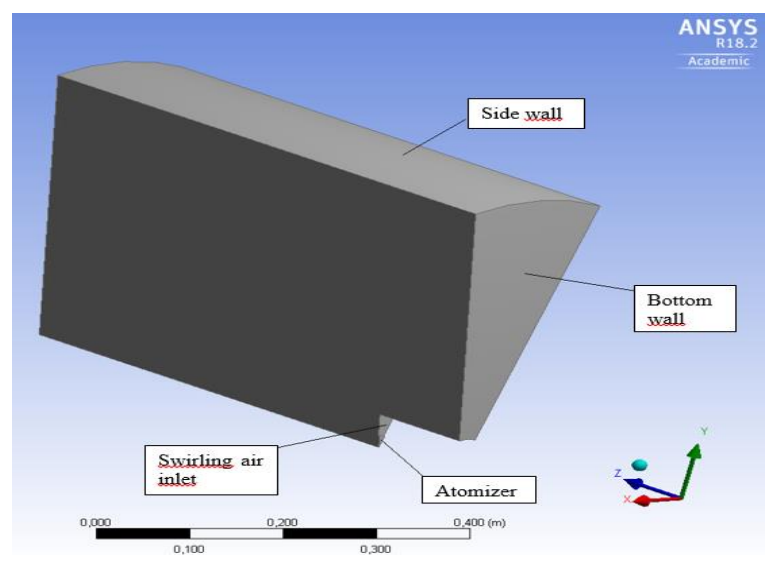

Figure 3. CAD of the $30^{\circ}$ sector that represents the computational domain

\subsection{Mesh}

The domain is discretized by using a structured mesh, thus obtaining advantages in terms of numerical accuracy. The gas velocity components have been computed by employing three different grids, i.e. 47,376, 115,020 and 191,569 numerical cells. Figure 4 shows the grid with 115,020 cells. Figure 5 provides a comparison, in terms of axial gas velocity along the radial direction at $9.5 \mathrm{~mm}$ from the injector. The figure shows that the results obtained by using 115,020 cells are very close to those obtained by using 191,569 cells, but with a much less computational cost.

In addition to the structured mesh, some simulations with polyhedral elements have been carried out to point out the quality of such a mesh. This analysis is given in the Appendix.

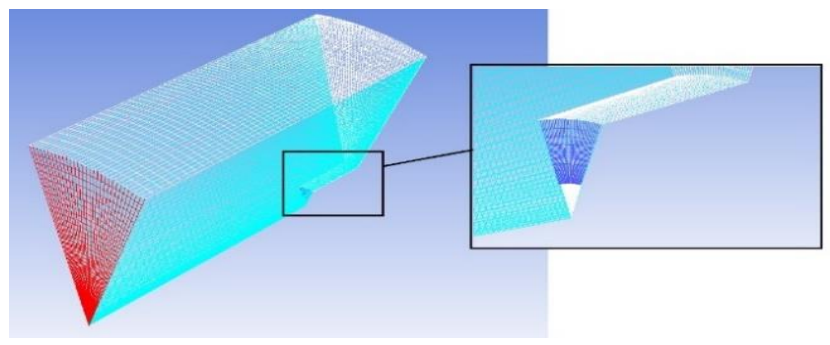

Figure 4. Structured mesh used for the simulations 


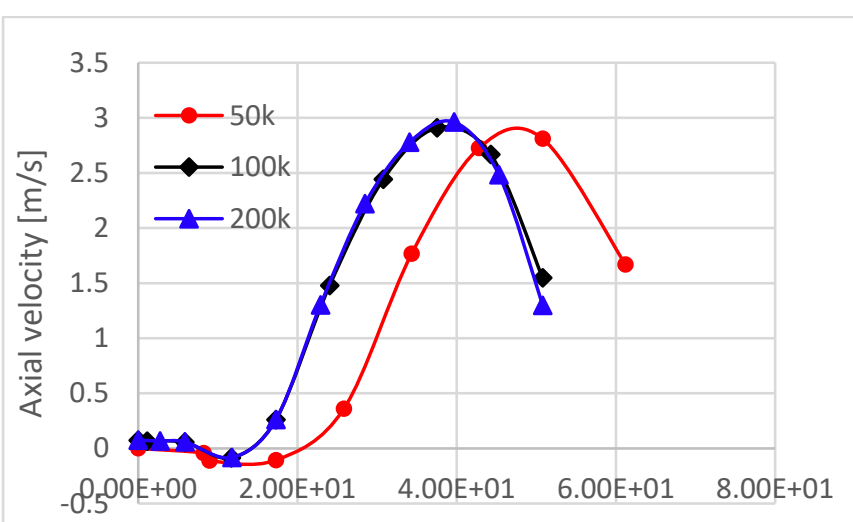

Radial coordinate $[\mathrm{mm}]$

Figure 5. Gas axial velocity component at $9.5 \mathrm{~mm}$ from the injector exit

\section{MODEL VALIDATION}

The model validation follows 3 steps: first only air injection is considered, then fuel injection has been added without combustion and, finally, combustion is taken into account.

\subsection{Turbulence model validation}

The first comparison regards only air inflow. As concerns the boundary conditions, the inlet air velocity profile is provided from the measurements and, at the exit, an open boundary with pressure equal to 1 bar is considered. The noslip condition is set along the walls and the symmetry boundary condition is set on the remaining boundaries. In the combustor, initial air temperature is set equal to $300 \mathrm{~K}$. At the inlet, the turbulence intensity is set equal to $30 \%$ of the mean velocity and a turbulence length scale of $2 \mathrm{~mm}$ (which is about $7 \%$ of the inlet diameter) is assumed. As regards initial conditions, inside the burner null velocity and pressure equal to 1 bar have been imposed.

A numerical scheme with a spatial second order accuracy has been used to solve the steady RANS partial differential equations.

The computations have been carried out by double precision format and reach convergence in about 1000 iterations (with a maximum value of the residuals set to $10^{-3}$ as a convergence criterion).

Figure 6 and Figure 7 show the comparison between CFD results and experimental data in terms of axial component of air velocity at an axial distance from the injector exit equal to $17.6 \mathrm{~mm}$ and radial component of velocity at an axial distance from the injector exit equal to $9.5 \mathrm{~mm}$, respectively. The results show a good agreement with the experimental profiles. However, some discrepancies are found related to the simplified CAD model used for the numerical simulations, which does not take into account the actual shape of the injector and a flow recirculation in the upper region of the burner due to the limitation on the height of the computational domain. Finally, the air velocity boundary conditions given by NIST provides an RMS equal to $0.1 \mathrm{~m} / \mathrm{s}$, with peaks equal to $0.2 \mathrm{~m} / \mathrm{s}$ for the inlet air velocity profile. Such an error is of the same order of the boundary conditions accuracy between CFD and the experimental data.

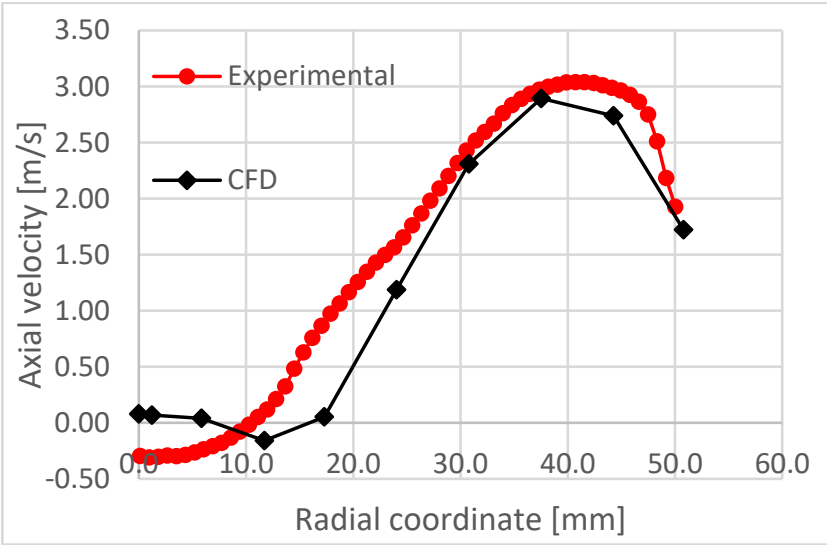

Figure 6. Air axial velocity component without fuel injection at $17.6 \mathrm{~mm}$ from the injector exit

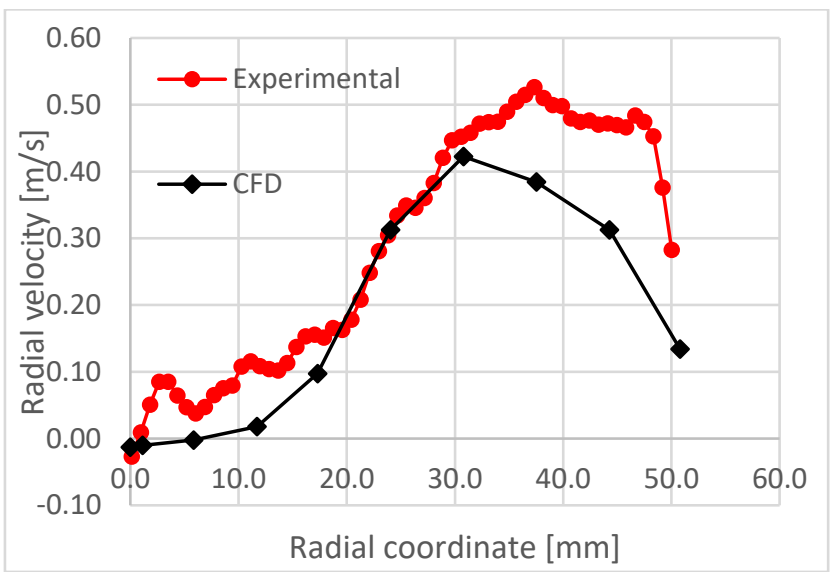

Figure 7. Air radial velocity component without fuel injection at $9.5 \mathrm{~mm}$ from the injector exit

\subsection{Injection model validation}

The injected mass flow rate of methanol is equal to 8.33 $10^{-4} \mathrm{~kg} / \mathrm{s}$, with a temperature of $295 \mathrm{~K}$. The injection pressure is equal to $689 \mathrm{kPa}$ and a spray included half-angle of $30^{\circ}$.

The pressure swirl atomization process is simulated by using LISA (Linearized Instability Sheet Atomization) model. Some model parameters can be adjusted in order to get a good agreement with the experimental data in terms of Sauter mean diameter distribution and velocity profile of the droplets:

(1) Dispersion angle: $10^{\circ}$

(2) Sheet constant: 12

(3) Ligament constant: 0.5

(4) Injector diameter: $0.00178 \mathrm{~m}$.

Figure 8 shows the comparison between computations and measurements in terms of droplets Sauter mean diameter distribution in the radial direction at $25 \mathrm{~mm}$ from the injector exit. The simulation provides a profile that qualitatively follows the experimental data. However, the SMD is always underestimated with respect to the measured one and this is also found at other axial distances from the injector. Zhu et al. [21] recovered, for the same simulation, an opposite trend, i.e. their Sauter mean diameter was slightly larger than the experimental SMD. However, the results of Zhu et al. do not reproduce the experimental distribution of droplets in the radial direction. Further investigations are required to better predict the SMD distribution, but this goes beyond the scope of this work. 


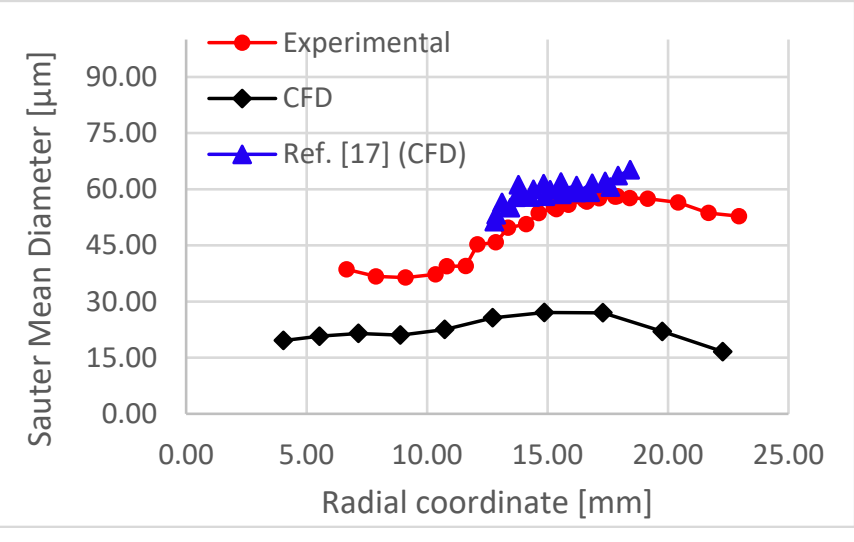

Figure 8. Sauter mean diameter of injected droplets at 25 $\mathrm{mm}$ from the injector exit

Figure 9 shows a comparison between numerical and experimental results in terms of axial velocity of the injected droplets at $15 \mathrm{~mm}$ from the injector exit. Since the droplets are injected with statistically random trajectories at random times, the velocity profile has been obtained by a sampling of all droplets that passed through a cross-section at a certain distance from the injector exit. All the sampled velocity data have been approximated by a $4^{\text {th }}$ order polynomial. Figure 9 shows that the agreement with the experimental profile is good.

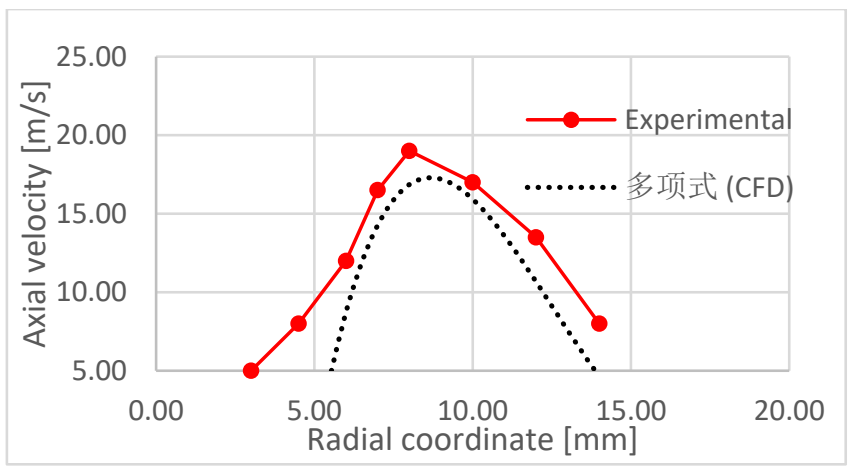

Figure 9. Axial velocity profile of injected droplets at $15 \mathrm{~mm}$ from the injector exit

\subsection{Combustion model validation}

Unsteady simulations of combustion of methanol in the burner have been performed. Figure 10 shows the temperature distribution inside the burner at different time instants.

Initially, the flame develops by following the hollow cone structure of the injector. Then the pressure field moves the flame towards the axis. At about $2.0 \mathrm{~s}$, another region appears where combustion takes place. This is a consequence of some fuel droplets that, after injection, reach such a zone before evaporating. When their temperature reaches the vaporization temperature, fuel mixes with air and auto-ignition occurs. It is believed that those droplets would exit from the burner with a different value for pressure along the outlet boundary and/or by enlarging the computational domain. However, experimental data are not available in the region above the flame and final conclusions cannot be drawn.

Figure 11 shows a comparison between numerical results and experiments in terms of axial gas velocity radial profiles at $9.5 \mathrm{~mm}$ from the injector exit. A good agreement is obtained, except for the region near the axis. This is due to the simplified
CAD model that does not take into account the actual shape of the injector.

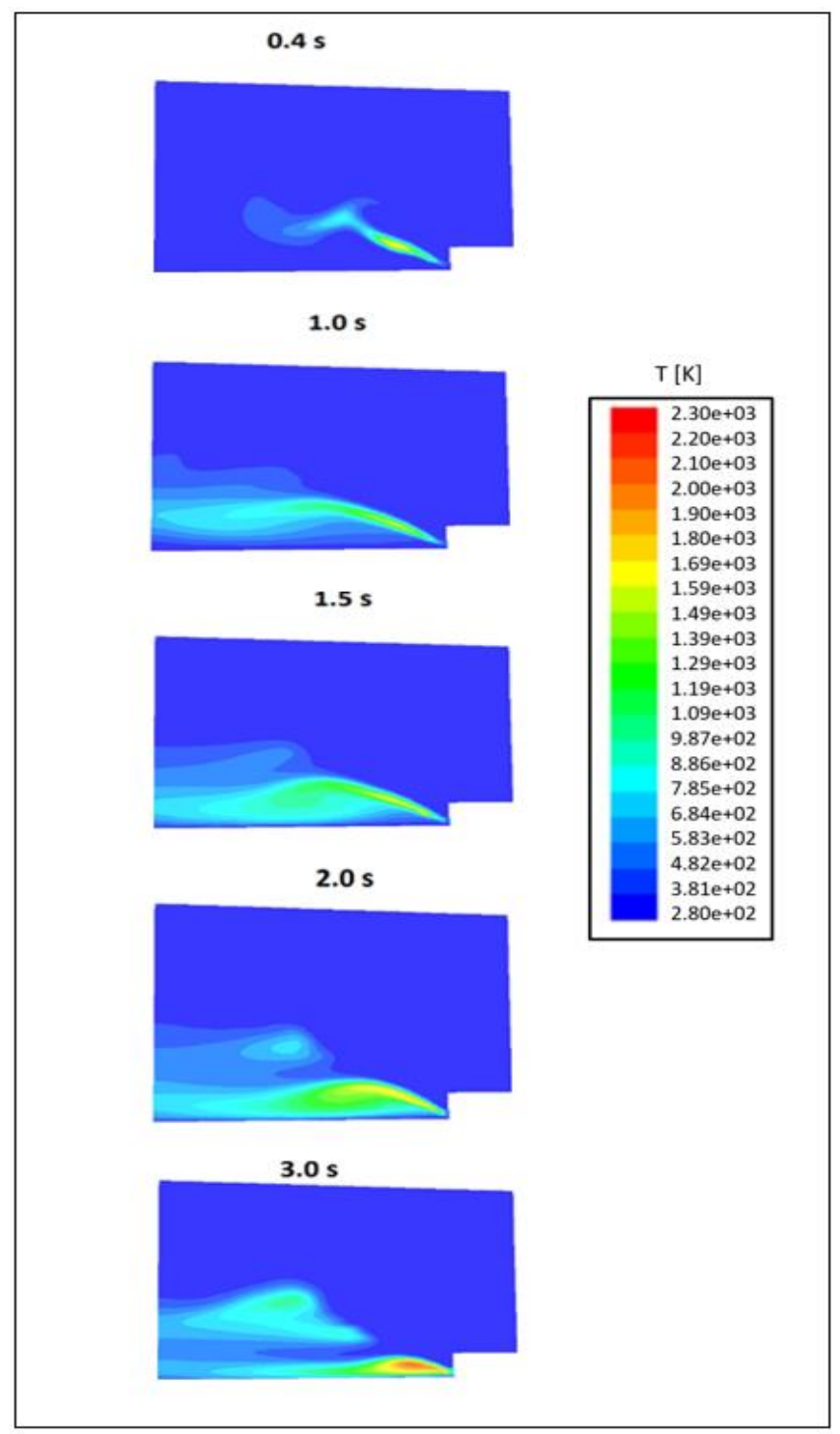

Figure 10. Methanol combustion: temperature distribution at different time instants

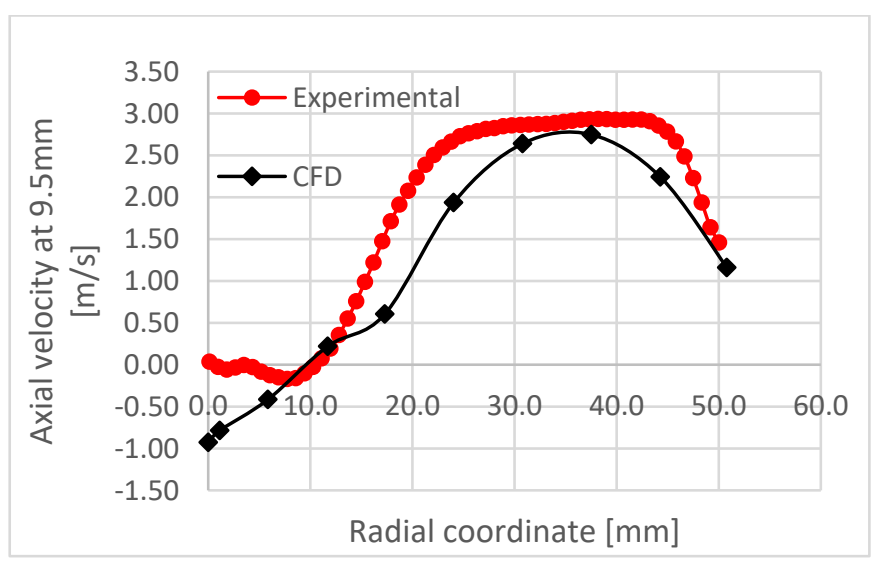

Figure 11. Gas axial velocity profile at $9.5 \mathrm{~mm}$ from the injector exit (with combustion) 


\section{BIODIESEL COMBUSTION}

At first, the same setup used for methanol injection has been employed for biodiesel, in order to highlight the different outcomes.

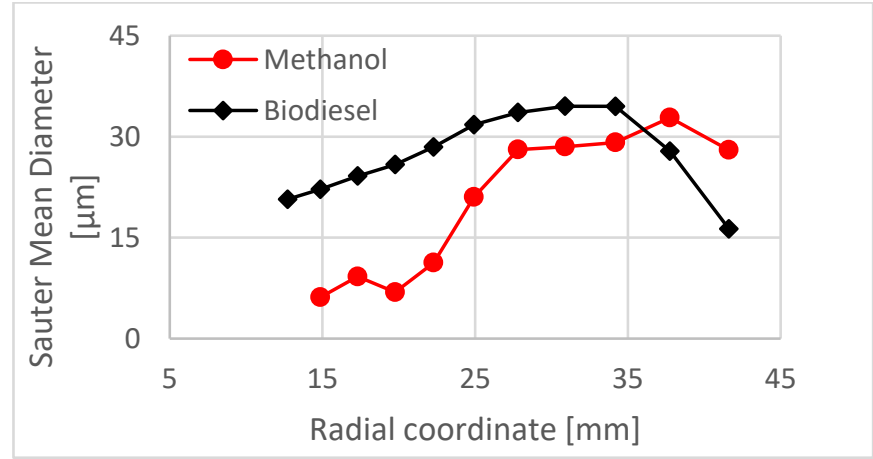

Figure 12. Comparison between methanol and biodiesel droplets Sauter mean diameter at $55 \mathrm{~mm}$ from the injector exit

Figure 12 shows a comparison between methanol and biodiesel in terms of radial distribution of Sauter mean diameter at $55 \mathrm{~mm}$ from the injector exit. As expected, the Sauter mean diameter of biodiesel droplets is larger than SMD of methanol, based on the physical properties of the fuel. The radial distribution of droplets axial velocity of biodiesel and methanol fuels are compared at $35 \mathrm{~mm}$ from the injector in Figure 13. The maximum droplets velocity is less for biodiesel, but the profile is smoother than that of methanol.

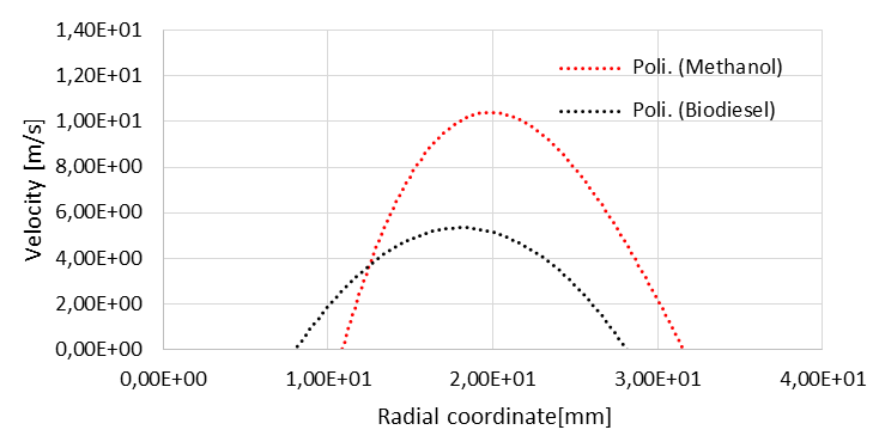

Figure 13. Comparison between methanol and biodiesel droplets axial velocity at $35 \mathrm{~mm}$ from the injector exit

The temperature distributions at steady state for biodiesel and methanol combustion are compared in Figure 14. Large differences are recovered, due to the different properties of the two fuels. The biodiesel flame follows the hollow-cone direction and reaches the top burner wall.

In order to improve the biodiesel combustion, a parametric study is carried out by varying the air inlet velocity components and the injection angle. The aim of this analysis is to select an injection configuration to get an optimal biodiesel combustion, both in terms of pollutant emissions and temperature distribution. The axial and tangential components of the inlet air have been reduced by a factor of 0.5 and 0.25 , whereas the injector included half-angle has been reduced to $20^{\circ}$ and $10^{\circ}$. By considering all possible cases, eight more simulations have been performed. The results have been analysed by computing the amount of fuel, $\mathrm{CO}_{2}, \mathrm{H}_{2} \mathrm{O}$ and other intermediate species and the flame temperature distribution.
The results show that in order to obtain a flame structure similar to methanol, the injection angle and the inlet air velocity have to be reduced with respect to the baseline case. Figure 15 shows the temperature distribution obtained with an injector included half-angle equal to $10^{\circ}$ and with both axial and tangential components of the inlet air reduced by $75 \%$. Figure 16 shows the temperature distribution obtained with the injector included half-angle equal to $20^{\circ}$ and the axial and tangential components of the inlet air reduced by $50 \%$.

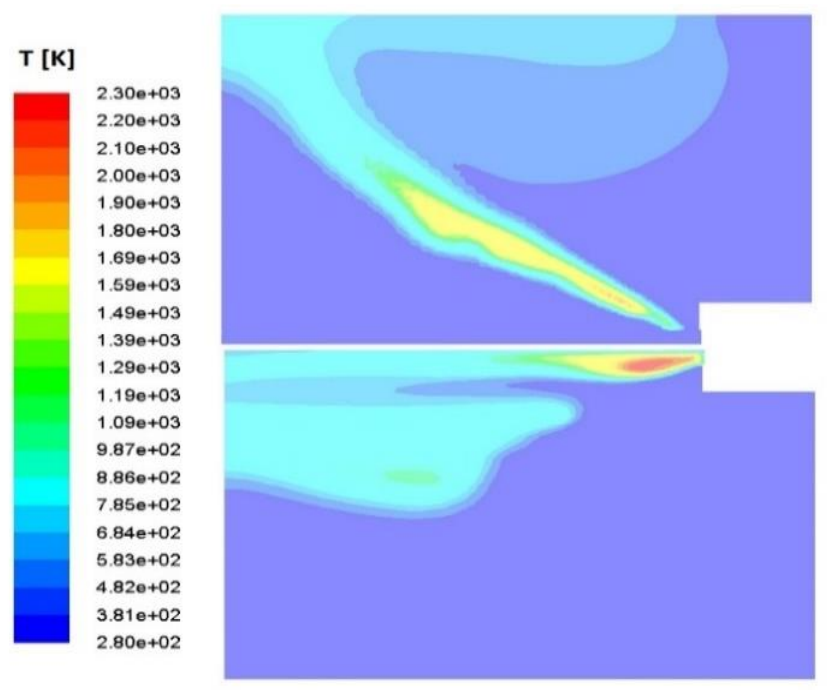

Figure 14. Biodiesel combustion temperature distribution (top) and methanol (bottom)

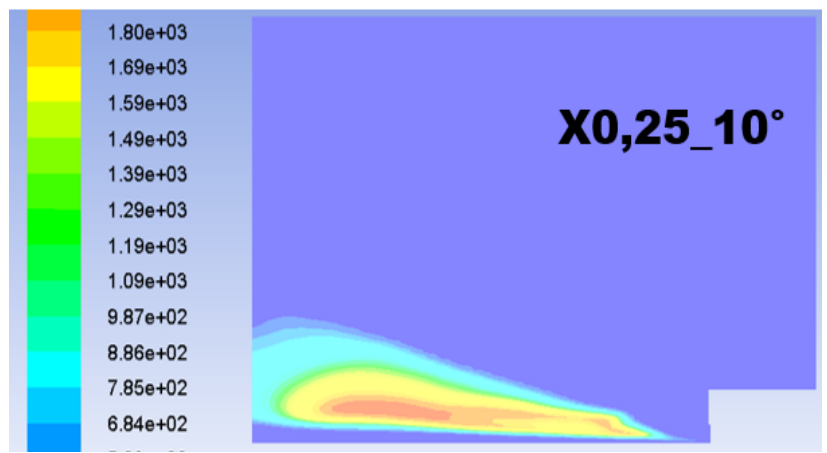

Figure 13. Temperature distribution for biodiesel combustion with $10^{\circ}$ included half-angle injection and axial and tangential components of the inlet air reduced by $75 \%$

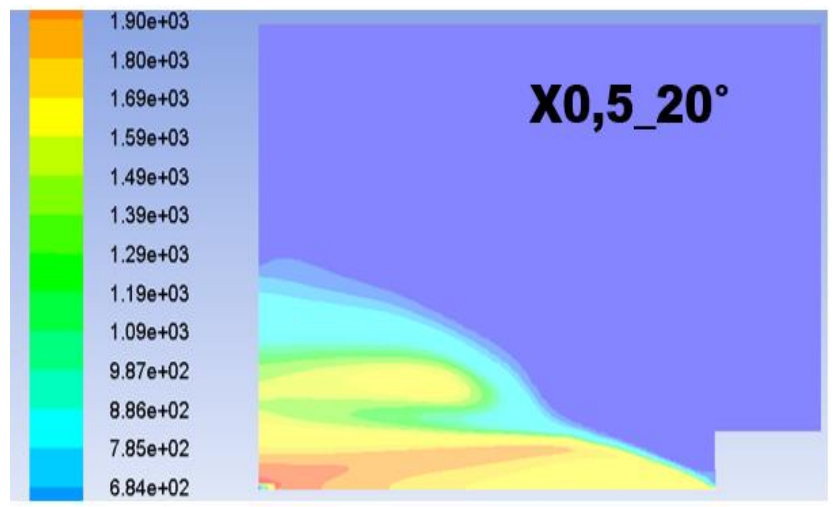

Figure 14. Temperature distribution for biodiesel combustion with $20^{\circ}$ included half-angle injection and axial and tangential components of the inlet air reduced by $50 \%$ 
Finally, Figure 17 shows the amount of methyl decanoate and $\mathrm{CO}_{2}$ in the combustion chamber at the end of the simulation. In the case with the tangential and axial components of the inlet air reduced by $75 \%$, the residual fuel mass is very low, thus indicating that the combustion is more efficient than the other cases. With the tangential and axial components of the inlet air reduced by $50 \%$ and with an injection half-angle equal to $20^{\circ}$ a more efficient combustion is obtained with respect to the case with the injection halfangle of $10^{\circ}$.
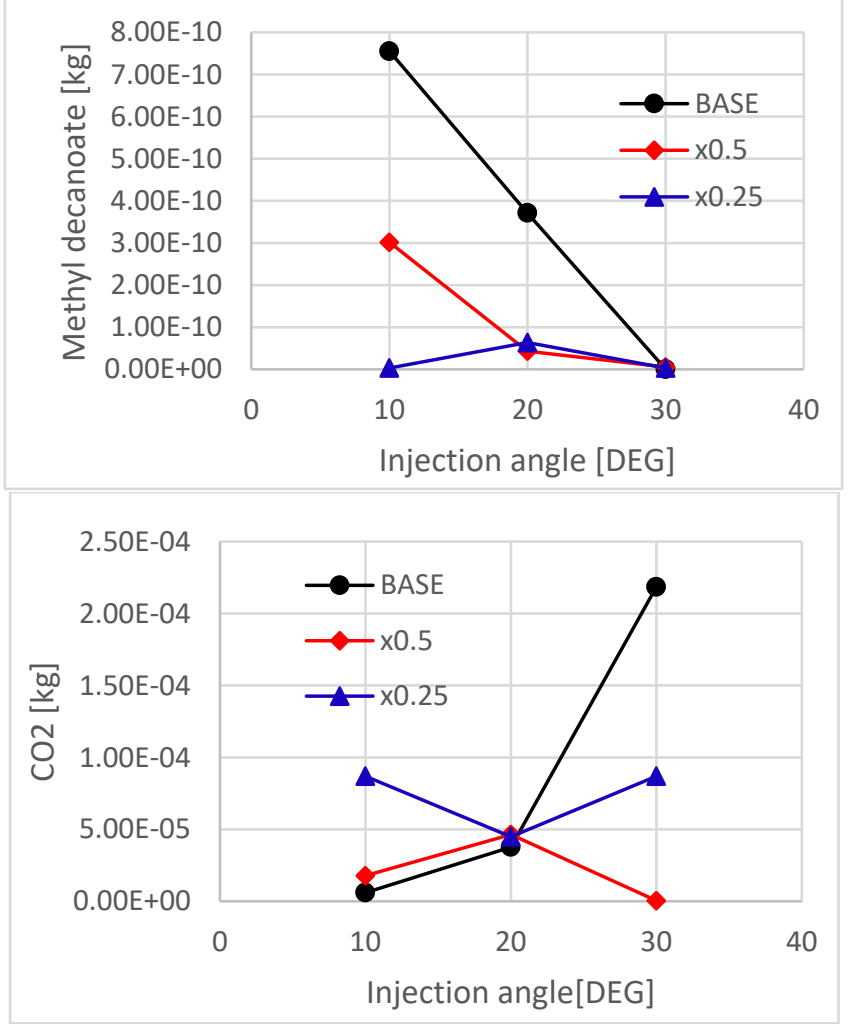

Figure 15. Methyl decanoate and $\mathrm{CO}_{2}$ in the combustion chamber for different configurations (base $=$ baseline case, $\mathrm{x} 0.5=$ axial and tangential components of the inlet air reduced to $1 / 2, x 0.25=$ axial and tangential components of the inlet air reduced to $1 / 4$ )

\section{APPENDIX}

\subsection{Polyhedral mesh}

In this appendix, the results of the structured mesh are compared with those obtained by using a polyhedral mesh. Starting from a mesh with 283,401 tetrahedral cells and a higher cells density along the axis, created with the "body of influence" method, a polyhedral mesh is obtained with the command "Make Polyhedra". This command executes various operations on the mesh with the aim to improve its quality. First, it decomposes all the cells in "duals" that are subvolumes of the original cells. After that, the duals are combined in order to get the polyhedral cells. Based on this procedure, the software is able to optimize the shape of each cell, resulting in a reduced skewness. In addition, polyhedral cells have a higher number of neighbor cells, which allows to have a better approximation of the gradients in every direction. In addition, the Make Polyhedra command uses the reversed
Cuthill-McKee algorithm in order to convert a sparse matrix to a band matrix, which can be solved faster by a numerical point of view. The mesh creation process is shown in Figure 18. The final polyhedral mesh used for the simulation has 54,517 cells and gives results similar to those obtained with the structured mesh with 115,020 cells, as shown in Figure 19, which compares the air axial velocity at $9.5 \mathrm{~mm}$ from the injector exit, in the case without fuel injection, obtained with the structured mesh, the polyhedral mesh and the measurement. This result suggests to further explore the convenience of using a polyhedral mesh instead of a structured mesh.

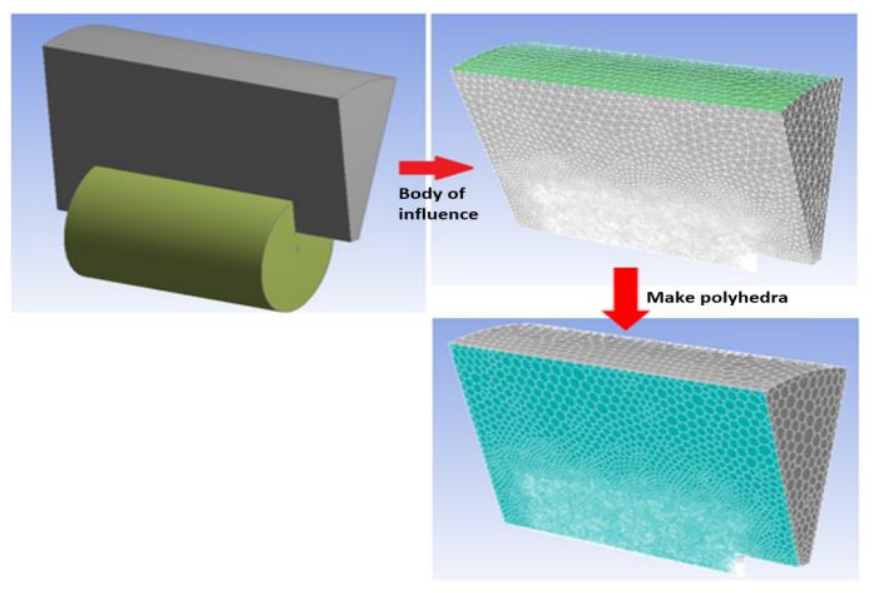

Figure 16. Polyhedral mesh creation process

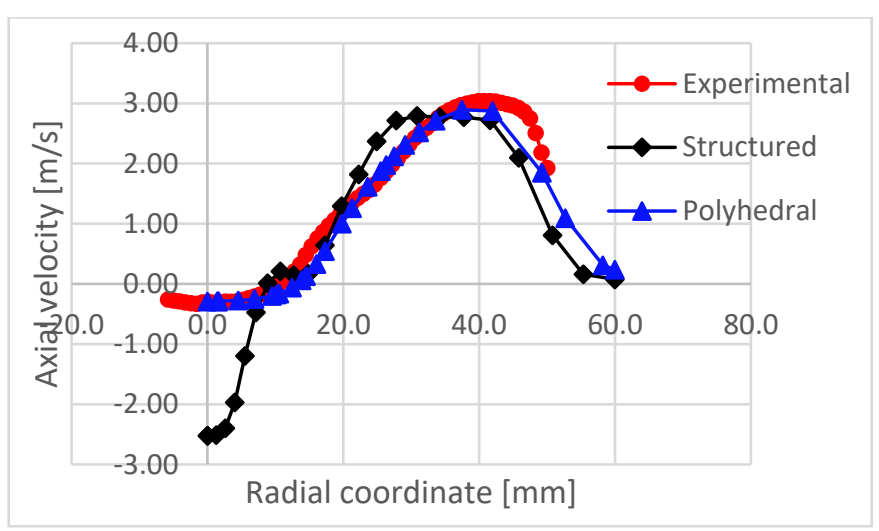

Figure 17. Comparison among measurements, structured mesh and polyhedral mesh for the air axial velocity at 9.5 $\mathrm{mm}$ from the injector exit without fuel injection

\section{CONCLUSIONS}

The aim of this work is to analyse the characteristics of biodiesel combustion in industrial burners, in order to optimize the overall combustion process. This work is a starting point towards the optimization of biodiesel combustion in industrial burners. A CFD model has been employed to simulate the fuel combustion in a burner. The burner designed by NIST has been used as test case with both methanol and biodiesel as fuels. As expected, the results of the simulations show that biodiesel droplets vaporize slowly with respect to methanol drops. Besides, biodiesel has higher liquid viscosity and density than methanol, therefore, the spray injection angle and the air inlet velocity must be reduced with respect to methanol to obtain a similar flame structure. Moreover, the reduction of the injection angle and velocity results in more compact 
burners. The flame structure and temperature distributions of the optimal configuration show that biodiesel could be employed for such burners. The fuel consumption and $\mathrm{CO}_{2}$ emissions have been computed in order to assess the efficiency of the combustion process.

Overall, this preliminary study provides some important guidelines in order to design an experimental test-bench for biodiesel combustion in industrial burners. Such an apparatus could be also used to provide more detailed experimental data on the biodiesel combustion process in order to further validate the numerical model developed in this work.

\section{REFERENCES}

[1] GSE. (2015). statistical report: Energy from renewable sources. GSE. Rome, Italy.

[2] Gao L, Xu W, Xiao G. (2017). Modeling of biodiesel production in a membrane reactor using solid alkali catalyst. Chem Eng. and Processing: Proc Intens. 122: 122-127. https://doi.org/10.1016/j.cep.2017.09.019

[3] Shah AP, Patil SD. (2017). Performance, emission and combustion analysis of biodiesel extracted from acidic oil: A by-product of soybean oil refining process. Modelling Measurement and Control C 78(3): 337-350. https://doi.org/10.18280/mmc_c.780306

[4] Farobie O, Matsumura Y. (2017). State of the art of biodiesel production under supercritical conditions. Prog in Energy and Comb Science 63: 173-203. https://doi.org/10.1016/j.pecs.2017.08.001

[5] Zhang Y, Dubé MA, McLean DD, Kates M. (2003). Biodiesel production from waste cooking oil: 1. Process design and technological assessment. Bioresource Technology 89(1): 1-16. https://doi.org/10.1016/S09608524(03)00040-3

[6] da Silva César A, Werderits DE, de Oliveira Saraiva GL, da Silva Guabiroba RC. (2017). The potential of waste cooking oil as supply for the Brazilian biodiesel chain. Renewable and Sustainable Energy Reviews 72: 246-253. https://doi.org/10.1016/j.rser.2016.11.240

[7] Hajjari M, Tabatabaei M, Aghbashlo M, Ghanavati H. (2017). A review on the prospects of sustainable biodiesel production: A global scenario with an emphasis on waste-oil biodiesel utilization. Renewable and Sustainable Energy Reviews 72: 445-464. https://doi.org/10.1016/j.rser.2017.01.034

[8] Fanelli E, Viggiano A, Braccio G, Magi V. (2014). On laminar flame speed correlations for $\mathrm{H}_{2} / \mathrm{CO}$ combustion in premixed spark ignition engines. Applied Energy 130: $166-180$ https://doi.org/10.1016/j.apenergy.2014.05.012

[9] Kurji H, Valera-Medina A, Okon A, Chong CT. (2017). Combustion and emission performance of $\mathrm{CO} 2 / \mathrm{CH} 4 /$ biodiesel and $\mathrm{CO}_{2} / \mathrm{CH}_{4} /$ diesel blends in a swirl burner generator. Energy Procedia 142: 154-159. https://doi.org/10.1016/j.egypro.2017.12.025

[10] Toledo M, Jiménez J, Cardenas L, Gers R, Espinoza J. (2015). Combustion of biofuels-diesel blends in an isothermal oven. Global NEST Journal 16: 1145-1151.

[11] Zadmajid S, Albert-Green S, Afarin Y, Thomson MJ. (2017). Optimizing a swirl burner for pyrolysis liquid biofuel (bio-oil) combustion without blending. Energy and Fuels 31(6) https://doi.org/10.1021/acs.energyfuels.6b03417
[12] Genjehkaviri A, Jaafar MNM, Hosseini SE, Musthafa AB. (2016). Performances evaluation of palm oilbased biodiesel combustion in an oil burner. Energies 9(2). https://doi.org/10.3390/en9020097

[13] Widmann JF, Presser C. (2002). A benchmark experimental database for multiphase combustion model input and validation. Comb and Flame 129(1-2): 47-86. https://doi.org/10.1016/S0010-2180(01)00374-1

[14] Widmann JF, Presser C, Charagundla SR. (1999). Benchmark experimental database for multiphase combustion model input and validation: Baseline case. NIST, https://www.nist.gov/publications/benchmarkexperimental-database-multiphase-combustion-modelinput-and-validation.

[15] Widmann JF, Presser C, Charagundla SR. (1999). Benchmark experimental database for multiphase combustion model input and validation: Characterization of the inlet combustion air. NIST. https://www.nist.gov/publications/benchmarkexperimental-database-multiphase-combustion-modelinput-and-validation-1

[16] Abraham J, Magi V. (1997). Computations of transient jets: RNG k- Model versus standard k- Model. SAE Transactions 106: 1442-1452. https://doi.org/10.4271/970885

[17] Ansys Fluent Theory Guide. ANSYS Inc.

[18] Han Z, Perrish S, Farrell VP, Reitz RD. (1997). Modeling atomization processes of pressure-swirl hollow-cone fuel sprays. Atomization and Sprays 7(6): 663-684. https://doi.org/10.1615/AtomizSpr.v7i6.70

[19] O’Rourke PJ. (1981). Collective drop effects on vaporizing liquid sprays. Ph.D. dissertation, Princeton University, NJ, USA.

[20] Luo Z, Lu TF, Maciaszek MJ, Som S, Longman DE. (2010). A reduced mechanism for high temperature oxidation of biodiesel surrogates. Energy \& Fuels 24(12): 6283-6293. https://doi.org/10.1021/ef1012227

[21] Zhu S, Roekaerts DJEM, Th.H. Van Der Meer. (2011). Numerical simulation of a turbulent methanol spray flame using the Euler-Lagrange method and the steady laminar flame let model. Presented at Conference: Proceedings of the Mediterranean Combustion Symposium. At: Chia Laguna, Sardinia, Italy.

\section{NOMENCLATURE}

\begin{tabular}{|c|c|}
\hline $\mathrm{C}_{\mathrm{b}}$ & $\begin{array}{l}\text { Droplet distortion model parameter, } \\
\text { dimensionless }\end{array}$ \\
\hline $\mathrm{C}_{\mathrm{D}}$ & Drag coefficient, dimensionless \\
\hline $\mathrm{C}_{\mathrm{D}, \mathrm{sph}}$ & $\begin{array}{l}\text { Perfect sphere drag coefficient, } \\
\text { dimensionless }\end{array}$ \\
\hline $\mathrm{C}_{\mathrm{d}}$ & TAB model parameter, dimensionless \\
\hline $\mathrm{C}_{\mathrm{F}}$ & TAB model parameter, dimensionless \\
\hline $\mathrm{C}_{\mathrm{k}}$ & TAB model parameter, dimensionless \\
\hline$\overline{\mathrm{D}}$ & $\begin{array}{l}\text { Arithmetic mean diameter between two } \\
\text { droplets, } m\end{array}$ \\
\hline $\mathrm{d}_{0}$ & Most probable droplet diameter, $\mathrm{m}$ \\
\hline $\mathrm{d}_{\mathrm{inj}}$ & Injector orifice diameter, $\mathrm{m}$ \\
\hline $\mathrm{k}$ & Turbulent kinetic energy, $\mathrm{J} \mathrm{kg}^{-1}$ \\
\hline $\mathrm{k}_{\mathrm{V}}$ & $\begin{array}{l}\text { Velocity coefficient for LISA model, } \\
\text { dimensionless }\end{array}$ \\
\hline$\dot{\mathrm{m}}$ & Injection mass flow rate, $\mathrm{kg} . \mathrm{s}^{-1}$ \\
\hline & Droplet radius, $\mathrm{m}$ \\
\hline
\end{tabular}


Liquid sheet thickness, $\mathrm{m}$

Injected fluid velocity axial component at the injector exit, $\mathrm{m} . \mathrm{s}^{-1}$

Droplet velocity magnitude, $\mathrm{m} . \mathrm{s}^{-1}$

Relative velocity magnitude between two droplets, $\mathrm{m} . \mathrm{s}^{-1}$

Weber collision number, dimensionless

Droplet characteristic dimension, $\mathrm{m}$

Droplet distortion parameter,

dimensionless

\section{Greek symbols}

$\Delta \mathrm{p}$

$\varepsilon$

$\theta$

$\mu_{1}$

$\rho_{\mathrm{g}}$

$\rho_{1}$

$\sigma$
Pressure drop at the injector exit, $\mathrm{kg} . \mathrm{s}^{-2}$. $\mathrm{m}^{-1}$

Turbulent energy dissipation rate, $\mathrm{J} \mathrm{kg}^{-}$ ${ }^{1} \cdot \mathrm{s}^{-1}$

Injection angle, rad

Liquid phase viscosity, $\mathrm{kg} \cdot \mathrm{m}^{-1} \cdot \mathrm{s}^{-1}$

Gas phase density, kg. m-3

Liquid phase density, $\mathrm{kg} . \mathrm{m}^{-3}$

Droplet surface tension, $\mathrm{kg} \cdot \mathrm{s}^{-2}$ 